\title{
Alejandría y el conocimiento libresco en las ktíseis de Plutarco y Pseudo Calístenes
}

\author{
Ivana S. Chialva \\ Universidad Nacional del Litoral (UNL) - CONICET \\ ichialva@gmail.com \\ ORCID iD: http://orcid.org/0000-0001-8880-8108
}

\begin{abstract}
Alexandria and the bookish knowledge in ktiseis of Plutarch and Pseudo Callisthenes
\end{abstract}

Este trabajo analiza de qué manera dos relatos de la tradición indirecta de la vida de Alejandro Magno, Plutarco (Alex.) y Pseudo Calístenes (recensión $\beta$ ), reelaboran el momento de la fundación (ktísis) de la capital egipcia, Alejandría. Se intentará demostrar cómo ambas versiones retrabajan la transmisión de las fuentes e in-scriben en su propio relato la importancia de la letra escrita y del conocimiento libresco (que caracteriza a la ciudad en el período helenístico y romano) en las circunstancias literales y literarias de la fundación. De esta manera, el mundo imperial se pre-dice en el origen de la gran ciudad y favorece una imagen de continuidad con el legado de Alejandro en el imaginario de las Alejandrías literarias.

Palabras Clave: Alejandría; ktísis; Plutarco; Pseudo Calístenes.
This article analyzes how two accounts of the indirect tradition of Alexander's life (Plu., Alex.; Ps. Callisth., $\beta$ ) re-elaborate the episode of the foundation (ktisis) of Alexandria, the Egyptian capital. An attempt will be made to show how both versions modify the sources transmission and inscribe in their own account the importance of the written word and bookish knowledge (which characterizes the city in the Hellenistic and Roman period) in the literal and literary circumstances of the foundation. Thus, the imperial world is predicted at the origin of the big city and promotes an image of continuity with the legacy of Alexander in the imaginary of the literary Alexandrias.

Key words: Alexandria; ktisis; Plutarch; Pseudo Callisthenes.

Cómo citar este artículo / Citation: Chialva, Ivana S. 2017: «Alejandría y el conocimiento libresco en las ktíseis de Plutarco y Pseudo Calístenes», Emerita 85 (1), pp. 49-71. 
A diferencia de otras ciudades antiguas, Alejandría, la capital egipcia, gozó de prestigio y reconocimiento como centro de civilización desde tiempos muy cercanos a su fundación en el año 331 a. C. ${ }^{1}$ Casi simultáneamente, la Alejandría histórica dio lugar a la Alejandría literaria en los testimonios de la tradición directa, i.e. los escritos de los 'compañeros' (hetaîroi) del rey macedonio, donde se mencionaban los orígenes de la pólis. Poco después, durante la época ptolemaica, esos relatos alimentaron los detalles, entre históricos y fabulosos, de las composiciones poéticas de las Alexandreías Ktíseis (Fundaciones de Alejandría), que circulaban como piezas autónomas y que constituían una práctica frecuente entre los autores de la Gran Biblioteca: así se deduce de los fragmentos de cinco Ktíseis (de Náucratis, Cnido, Cauno, Rodas y Lesbos) pertenecientes a Apolonio de Rodas, además de una Alexandreías ktísis (según un escolio de Nicandro) donde el mito fundacional incluía serpientes venenosas nacidas de la sangre de la Gorgona, evidente helenización de una versión egipcia sobre el origen de la ciudad². Simultáneamente, proliferaron los relatos de fundación en prosa, integrados en narraciones más amplias, donde se destacaban las nuevas características monumentales de la edificación urbana. Ya en tiempos del Imperio, el tópico de la descripción de la capital helenística devino en motivo frecuente en la enseñanza de los ejercicios retóricos: Aftonio, en sus Progymnásmata (s. IV d. C.), ofrece como modelo de ékphrasis tópou el recorrido por su acrópolis. El esplendor de la Alejandría literaria durante sus primeros siglos abarca una asombrosa cantidad de géneros (relatos de viajes, novelas eróticas, historiografías, biografías, paradoxografías, descripciones geográficas,

${ }^{1}$ Acerca del debate sobre la fecha exacta de la fundación (si fue en el mes de enero o abril) y los diferentes calendarios (egipcio, ptolemaico, romano) que intervienen en la datación, véase Jouanno 2002, p. 68.

${ }^{2}$ El tópos literario de la ktísis tiene antecedentes en la poesía arcaica, aunque siempre incluido en composiciones más extensas: poesía épica, elegía, himnos, epinicios, peanes, drama, etc. Al respecto, Dougherty 1994 plantea que es en época helenística cuando este motivo se convierte en un género poético autónomo, según los fragmentos conservados de ktíseis de Apolonio y Calímaco. La consolidación del género está ligada a dos razones, una histórica y la otra literaria: a) por la política de fundación de ciudades iniciada por Alejandro y seguida por los diádocos en el oriente mediterráneo; b) por el interés de los poetas alejandrinos en clasificar la poesía anterior, reunida ahora en la Biblioteca, y en celebrar las acciones de los reyes que impulsaban el desarrollo cultural en la metrópolis helenística. Para un estudio de las Ktíseis de Apolonio como género autónomo, véase Sistakou 2008. Para una visión de conjunto de estas obras y su innovación crítica meta-literaria, véase Whitmarsh 2004, pp. 122-138. 
encomios) y aún perdura cuando la supremacía intelectual de la ciudad y su grandiosa arquitectura han perdido notoriedad frente a otras urbes del mundo romano.

Si la Alejandría histórica deja ver, en las sucesivas construcciones y destrucciones, todas las luchas del proceso de sometimiento al poder de Roma, la Alejandría literaria, por su parte, ofrece un tópos que favorece el imaginario de la articulación cultural entre el mundo helenístico y el mundo imperial. La metrópolis de Alejandro es modelo de civilización a imitar en los comienzos del Imperio, cuando Diodoro de Sicilia (s. I a. C.) la considera la prime-

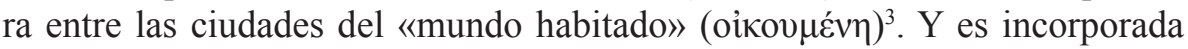
como parte de la romanidad cuando, casi dos siglos después, Elio Arístides asegura, en su Elogio a Roma, que Alejandro fundó la capital con el fin de que los romanos tuvieran la gloria de conquistar la ciudad más grande después de la suya ${ }^{4}$. La asimilación de la urbe egipcia al presente romano se percibe también en las reelaboraciones de los relatos de fundación por parte de los autores imperiales, i.e. la tradición indirecta, como es el caso de la Vida de Alejandro de Plutarco (Plu., Alex.) y de la Vida y Hazañas de Alejandro de Macedonia del Pseudo Calístenes (Ps. Callisth.), también conocida como Novela de Alejandro ${ }^{5}$. Ambos textos, enraizados en tradiciones narrativas muy diversas y con variantes significativas en la anécdota, presentan, no obstante, dos rasgos comunes: la justificación de las características de Alejandría en la figura del macedonio y la relación del destino cultural de la pólis con las circunstancias literarias o literales de su fundación. Mucho se ha dicho ya acerca de las escrituras de las vidas (bioi) de Alejandro en época romana y de su función como modeladoras de la imagen del buen rey ${ }^{6}$ para

${ }^{3}$ D.S. XVII 52.5: «Tomó tal incremento la ciudad en todo durante los años sucesivos, que es considerada por muchos la primera del mundo» (Guzmán Guerra 1986, p. 198).

${ }^{4}$ Aristid., Or. 26.26: «Dejó [Alejandro] una única obra como recuerdo digno de su propia naturaleza, la ciudad que lleva su nombre junto a Egipto. Haciendo bien, la fundó para vosotros, para que también tuvierais y fuerais dueños de la mayor ciudad que existe después de la vuestra» (Cortés Copete 1997, p. 229).

${ }_{5}^{5}$ Para las citas de los textos griegos seguimos: en el caso de Plu., la edición de Ziegler 1968; en el de Ps. Callisth., $\alpha$, la edición de Kroll 1926; y para Ps. Callisth., $\beta$, la edición de Bergson 1965. Las traducciones al español utilizadas son: para Plutarco, Guzmán Guerra 1986, y para el Pseudo Calístenes, García Gual 1995, salvo si se indica otra cosa.

${ }^{6}$ Acerca de la figura de Alejandro como ejemplo de buen rey y las ambivalencias de ese modelo político, cf. Plácido 1995; López Salvá 1997; Rodríguez Adrados 2000; Whitmarsh 2002 y Santana Henríquez 2005. 
los emperadores. Pero menos se ha advertido de qué manera el mundo imperial se in-scribe en los relatos de fundación de Alejandría y reelabora las versiones de ese hecho histórico imprimiéndole el signo civilizador de la letra griega y del libro (Mestre 2008) que es, para los pepaideuménoi de estos siglos, el verdadero legado del gran Alejandro y su metrópolis.

\section{Vida de Alejandro. Plutarco}

El bios de Plutarco es un claro exponente de esta forma discursiva donde la comprensión de los eventos históricos está ceñida al êthos del personaje biografiado, como lo explica el propio autor en el conocido prólogo a esta Vida. En un estudio anterior ${ }^{7}$ hemos afirmado que, de las ktiseis conservadas en las fuentes imperiales griegas y latinas 8 , la versión plutarquea es decididamente libresca en el sentido material y simbólico del término. Este bios se desarrolla según una lógica narrativa que, conceptualmente, podemos calificar de helenística: vincula «palabras y hechos» (lógoi kaì érga) como una metonimia de causa/consecuencia que proyecta lo que Alejandro lee (Homero, en primer lugar, tragedias y ditirambos, Alex. 8.3-4) en lo que Alejandro hace. Las lecturas del macedonio justifican sus acciones en la medida en que la grandeza de sus actos se alimenta de la grandeza de la paideía que lo ha formado: basta recordar, en el parágrafo 8 dedicado a la educación del héroe, el énfasis dado a sus cualidades lectoras y el episodio de la «llíada de la caja»" copia del poema homérico que Alejandro

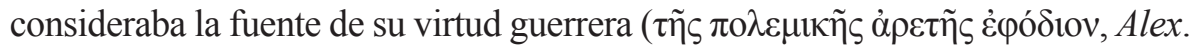
8.2) y que guardaba, junto con la espada, debajo de la almohada donde dormía. Pero más aún: el Alejandro de Plutarco no sólo se educa e inspira en Homero

${ }^{7}$ Chialva 2012.

${ }^{8}$ Arr., An. III 2; Curt. IV 8; Ps. Callisth. I 30-32, en las diversas recensiones helenísticas y proto-bizantinas.

${ }_{9}$ Plu., Alex. 8.2: «También manifestaba una inclinación natural a la literatura, y era amante de aprender y muy buen lector. Consideraba -y así llamaba- a la Ilíada vademecum del arte militar, y llevaba consigo un ejemplar corregido por Aristóteles que conocían con el nombre de «ejemplar de la caja», y que siempre tenía junto con el puñal bajo su almohada, según ha escrito Onesícrito». En De Alex. virt. I = 2.327f, Plutarco refiere que Ilíada y Odisea eran el equipo de campaña de Alejandro en los viajes. Aunque en la biografía, de posterior composición, el autor solamente menciona la primera de las obras, es significativo que en el sueño premonitorio de la ktísis se citan, precisamente, versos de la Odisea que Alejandro reconoce por su lectura del poema. Respecto de la interpretación homérica de Alejandro, por parte de Plutarco, véase De Alex. virt. II $=2.343 \mathrm{~b}$. 
sino que toma literalmente los versos de los poemas para comprender su propia realidad. Así, cuando llega a Troya (Alex. 15.7-9), busca la lira de Aquiles, aquella con la que el Pelida cantaba las hazañas de antiguos guerreros en el canto IX de la Ilíada. Esta interpretación literal reaparece en el parágrafo 26, dedicado a la fundación de la metrópolis. Efectivamente, la complementariedad de los términos lógoi kaì érga es el rasgo propio del período helenístico, que se materializará en la construcción de Alejandría y en su monumental proyecto libresco. Plutarco, desde la distancia temporal que le da su propio siglo, logra convertir ese cambio cultural en el principio narrativo de la Vida de Alejandro $\mathrm{y}$, especialmente, del relato de la fundación ${ }^{10}$.

La concepción helénica que Plutarco tiene del macedonio es coherente con el lugar asignado a la fundación en el periplo del viaje. El rey llega a Egipto y funda Alejandría antes de emprender la travesía al templo de Amón, primer momento de inflexión en el bíos que marca la creciente orientalización geográfica y subjetiva del macedonio. Ahora bien, el parágrafo 26 dedicado a la estancia en Egipto no sigue, como otras veces, un criterio cronológico: no relata directamente la fundación de la ciudad que es, según el orden fijado por Plutarco, la primera acción que Alejandro realiza allí. Por el contrario, introduce una digresión donde cuenta la anécdota de la lujosa caja que estaba entre los bienes de Darío y en la que Alejandro decide proteger su tesoro más valioso,

${ }^{10}$ Plu., Alex. 26.1-8: «Habiéndosele presentado una cajita, que era el objeto de mayor valor que habían encontrado los que custodiaban los tesoros y el ajuar de Darío, preguntó a sus amigos qué cosa les parecía la más digna de ser guardada en ella. Dijeron cada uno una cosa, mientras él dispuso que fuera la Ilíada la que allí se guardara. Esta anécdota la testimonian la mayoría de los autores más fidedignos. Y si lo que dicen los alejandrinos, apoyándose en la autoridad de Heraclides, es verdad, no parece que fuera Homero un compañero o consejero inútil en sus expediciones. Cuentan, en efecto, que una vez que conquistó Egipto, quiso fundar una ciudad que fuera grande y populosa, y denominarla según su propio nombre; y ya tenía casi medido y acotado el emplazamiento, según consejo de los arquitectos, cuando durante la noche, acostado, tuvo una visión maravillosa; le pareció que un anciano de canosa cabellera, de aspecto muy venerable, colocándose a su lado, le recitaba los siguientes versos: «Una isla hay allí que rodean las olas sin cuento: / Faro lleva por nombre y está frente a Egipto.»... Al contemplar, pues, lugar tan ventajoso y favorecido (se trata, en efecto, de una lengua de tierra regular y llana, semejante a un istmo, que separa de una parte un gran lago y de otra el mar que remata en un gran puerto) exclamó cómo Homero, que en lo demás era admirable, fue también el más sabio arquitecto, y a continuación ordenó diseñar el plano de la ciudad ajustándose a las características del terreno. Al no haber cal, tomaron harina y trazaron sobre la tierra negra un área semicircular, de cuya base interior partían unos radios que dividían uniformemente el arco, formando la figura de una clámide; ...» 
la Ilíada. Lo interesante de este desvío es que, en la linealidad narrativa, se articulan dos hechos que son distantes en el tiempo y el espacio (la obtención del arca en la batalla de Issos, posiblemente, y la fundación de Alejandría) y que Plutarco dispone en una relación metonímica causal (Larmour 2000). Literalmente, el texto griego dice: « ... y en verdad parece que Homero no fue ocioso ni dejó de contribuir sino que se asoció con él en la expedición» (ov̋Kovv

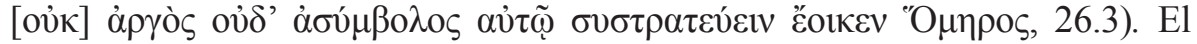
relato de la fundación, entonces, crea una lógica poética donde ese hecho histórico es presentado como una empresa conjunta de Alejandro y Homero mediante el recurso, tan frecuente en la literatura griega desde la épica, del sueño revelador. En palabras de Plutarco, Alejandro desea fundar en Egipto una «gran

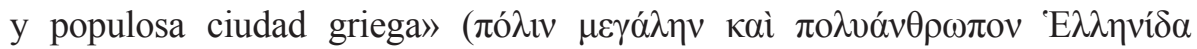

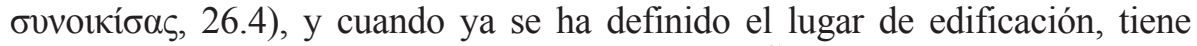

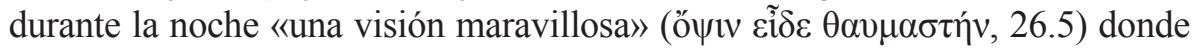

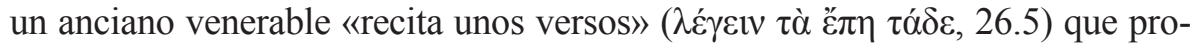
ceden (Plutarco no hace explícita la cita) del canto IV de la Odisea (IV 354 s.). Todo el pasaje es muy significativo ya que permite ver cómo entiende el Queronense aquel hecho y cómo matiza literariamente ese momento que él considera el inicio de una nueva etapa: el acto de la fundación de Alejandría. Gracias al sueño anticipatorio, Alejandro no construye la ciudad meramente sobre un tópos geográfico egipcio sino sobre un tópos poético griego. Alejandría queda, así, fundacionalmente concebida como una realización material de la paideía. Otra vez, lógoi kaì érga, exactamente en ese orden, es el motivo estructurante en la visión plutarquea de Alejandro. De allí que las cualidades del héroe civilizador se deriven de su condición de lector de la épica homérica. En el sueño, Homero recita unos versos, según conviene a la figura del poeta oral por excelencia en la cultura griega. Pero lo cierto es que el episodio encierra un giro de concepción helenística que modifica la herencia de la tradición clásica ya que Alejandro descifra quién es ese anciano de venerable aspecto por sus lecturas de los poemas homéricos: otra vez, el reconocimiento viene dado por la letra o, mejor dicho, por el conocimiento literal de la poesía. Es un juego de desciframiento que gira sobre el acto de la lectura en diferentes niveles, el anecdótico y el enunciativo, ya que seguramente Plutarco espera que el instruido lector del bios también reconozca la procedencia de esos versos. El matiz oral queda, así, subordinado al conocimiento libresco y a la memoria acopiada a través de la lectura. Podemos decir que, con el Homero del sueño de Alejandro, la función de la Biblioteca ha comenzado. 
El matiz literario y literal de la fundación modifica todos los detalles de la anécdota. Un ejemplo es la ékphrasis de la diagramación de la ciudad que, si bien sigue fuentes anteriores ${ }^{11}$, ahora queda ligada al episodio del sueño. Dice Plutarco que con cal sobre la negra tierra ${ }^{12}$ se trazaron sobre una base circular dos líneas rectas cerca de los bordes, de manera que el diseño resul-

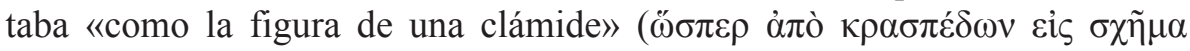
$\chi \lambda \alpha \mu v ́ \delta$ os, 26.8). Efectivamente, el contorno aproximadamente rectangular de la metrópolis es el más verosímil y es el que reproducen, hasta hoy, las reconstrucciones de los planos hipotéticos de la Alejandría helenística ${ }^{13}$. Pero aquí no sólo se destaca esa información, posiblemente histórica, sino el tratamiento dado para lograr que el perímetro urbano sea evidente y, a la vez, significativo a los ojos del lector: la ciudad es como una clámide y así el recurso de la ékphrasis tópou sella, asimismo, una identidad cultural. El Homero del sueño, que es el Homero literal de los textos, indica un lugar y

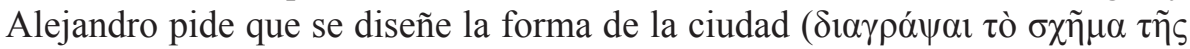
$\pi$ $\lambda_{\varepsilon \omega \varsigma, 26.7)}$ acomodada al sitio y entonces surge la forma de la clámide. La imagen urbana queda asociada no sólo a aspectos topográficos sino también poéticos y Homero deviene «un maravilloso y muy sabio arquitecto»

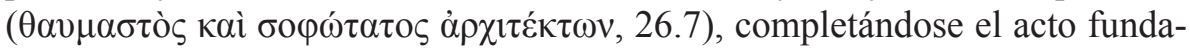
cional entre el poeta y el rey.

Finalmente, se cuenta el célebre episodio de la utilización de harina para delinear el perímetro de la edificación y la llegada de la multitud de pájaros que descienden y devoran el dibujo, lo que será interpretado por los adivinos como el presagio de la abundancia y el cosmopolitismo de la ciudad ${ }^{14}$. Así

${ }^{11}$ Cf. D.S. XVII 52.3; Str. XVII 1.8; Plin, $H N$ V 62.

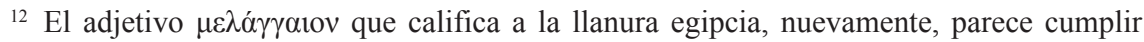
una función más poética que referencial y geográfica, ya que recuerda a la expresión homérica

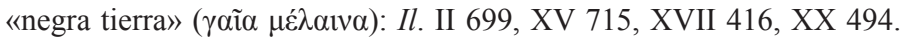

${ }_{13}$ Acerca de la debatida cuestión de la forma de la clámide, véase Tarbell 1906. Allí se analizan los diversos diseños según la información de las fuentes antiguas y se plantea que esa imagen dada para definir el contorno de Alejandría (D.S., Str., Plin. y Plu.,) puede estar ligada, más que a datos históricos, a concepciones imaginarias que los antiguos griegos tenían sobre los hechos ya que, p. ej., en Str. II 5.14 se utiliza la misma comparación de la clámide

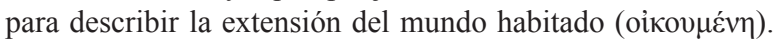

${ }^{14}$ Plu., Alex. 26.10: «Sin embargo, los adivinos le recomendaron tener confianza (la ciudad, en efecto, no sólo iba a tener abundantes recursos por sí misma, sino que iba a ser además nodriza ( $\tau \rho \circ \varphi o^{\prime}$ ) de gentes de otras partes), por lo que ordenó que los encargados empezaran las obras». 
se cierra el relato de fundación, anticipando el rol fundamental de esa zona y su prestigioso puerto en la provisión de alimentos en los siglos venideros, principalmente en el tiempo de Plutarco. Pero también aquí el término

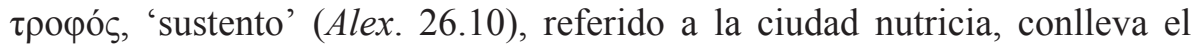
signo propiciatorio de la paideía que marca todo el pasaje. En esta versión helenizada de los acontecimientos, nada dice el autor de otras circunstancias, ya sean históricas o fabulosas, que integren elementos locales, como p. ej. el enclave de habitantes nativos llamado Rakotis, sobre el cual se asienta la nueva construcción. Tampoco nombra ningún episodio del conquistador con serpientes, historias que pueblan otras versiones de época helenística e imperial, como la ktísis de Apolonio (según Nicandro) y las recensiones $\alpha$ y $\beta$ del Pseudo Calístenes. Particularmente, esta ausencia es interesante ya que la serpiente, en este contexto, es un símbolo de Amón y Plutarco lo explicita cuando menciona las diferentes versiones sobre los hechos extraordinarios que signaron el momento de la concepción del héroe: primero, el rayo que cae sobre el vientre de Olimpia, como acto de gestación divina; luego, el sueño de Filipo, donde ve que sella el vientre de su mujer con la imagen de un león; y finalmente, en Alex. 2.6 y 3.1-3, el relato mítico que atribuye la paternidad de Alejandro al dios libio Amón, el cual se había unido a Olimpia transformado en serpiente (germen narrativo desarrollado en la Novela). Pero, nuevamente, el orden de las versiones sobre la concepción crea una visión helenizada del momento, ya que al dar cuenta de la afinidad de Olimpia con los ofidios se cuenta que: primero, se vio que un ser superior en forma de serpiente copuló con ella y a partir de allí Filipo comenzó a evitar su trato erótico (Alex. 2.6); segundo, la reina, impulsada por un fanatismo bárbaro, llevaba grandes serpientes en los tirsos y coronas de sus rituales órficos y en honor a Dioniso (Alex. 2.7-9); tercero, Filipo, tras haber visto el portento ( $\tau$ ò $\varphi \alpha ́ \sigma \mu \alpha . .$. Alex. 3.1, retoma lo dicho en 2.6), manda a consultar al oráculo de Delfos, donde se le dice que rinda honores a Amón y que perderá el ojo con el que vio al dios-serpiente unirse con su mujer (Alex. 3.1-3). Esta disposición tiene dos consecuencias en el relato: en primer lugar, se vincula la serpiente, ya sea por la vía ritual órfica o dionisíaca ya sea por la vía oracular Delfos-Amón, a las tradiciones religiosas helénicas. A su vez, la figura bárbara de Olimpia aparece no sólo como una bacante frenética sino que despierta reminiscencias homéricas, asociando su rol de mujer a lo extranjero, lo erótico, la magia y los animales. De este modo el episodio de la concepción queda sumido en una atmósfera mítica, muy conveniente al 
imaginario heroico de los antecesores familiares de Alejandro: Aquiles, Heracles y Dioniso. Por otro lado, la omisión de la serpiente en el parágrafo 26 tiene un efecto directo y es que desarticula el motivo de la fundación de Alejandría de otro hecho trascendente de Alejandro en Egipto: la visita al templo de Amón. Así, esos dos momentos se vuelven consecutivos en el relato biográfico pero no están ligados sustancialmente entre sí, a diferencia de lo que sucede en Pseudo Calístenes, donde hay una relación necesaria entre uno y otro. Es evidente la intención de Plutarco de evitar el matiz local egipcio en este momento, en especial si, como afirma el propio autor, seguía una fuente alejandrina para su versión de la ktísis: Heraclides Lembo, autor del s. II a. C. (Jouanno 2002, p. 102), quien transmite la versión del sueño homérico de Alejandro. La palabra, entonces, que rige todo el relato biográfico es continuidad: de la Grecia arcaica y clásica al reinado macedónico y, luego, al Imperio Romano. Para ello heleniza la figura de Alejandro y ese signo identitario se expresa en la impronta libresca de la fundación de la gran pólis. Tal herencia libresca es la que toma a su cargo Roma, en la visión del autor: no es otro el sentido de la imagen en la Vida de César (Caes. 49), el bios paralelo a Alejandro, del general romano que arriesga su vida para rescatar unos libros mientras ocurre el incendio de la ciudad que, según Plutarco, destruye la Gran Biblioteca.

\section{Vida y Hazañas de Alejandro de Macedonia. Pseudo Calístenes}

La versión del Pseudo Calístenes, en cambio, ofrece otro tipo de reformulación donde la clave es la imagen circular de la inmortalidad e implica la magia, la religión y la cultura letrada. A medio camino entre la historia y la fábula, la Novela fue escrita (en la primera versión conservada) por un autor alejandrino en el s. III d. C. y se la ha asociado al renacimiento del culto de Alejandro promovido por la dinastía de los Severos. No obstante, el material narrativo que dio lugar a la fábula debe haber tomado forma en época helenística, pocas décadas después de la muerte del macedonio (Stoneman 1994, 2008, Jouanno 2002). Como se trata de una obra de tradición abierta, existen cinco recensiones procedentes de diferentes momentos históricos: del período helenístico la recensión $\alpha \mathrm{y}$ del período proto-bizantino las recensiones $\beta$, $\lambda, \varepsilon, \gamma$ (Jouanno 2002). La más antigua, donde es predominante el elemento egipcio, es la recensión $\alpha$; sin embargo, nos interesa considerar principalmente la versión de ktísis que ofrece la recensión $\beta$, datada en el s. V d. C., y que 
ha sido considerada la reescritura griega de $\alpha^{15}$. Se trata de una versión más reducida y desprovista de la exaltación y del colorido local de aquella, debido a que el autor de $\beta$ no era de origen egipcio y sus lectores probablemente tampoco, lo que le da al texto un sesgo helenístico-romano, en sentido amplio.

En principio, ambas recensiones de la Novela introducen el rasgo bibliófilo de Alejandro, como expresión metonímica de su pertenencia a Egipto, desde el momento de la concepción del héroe: el relato del sueño de Filipo es más complejo que el dado por Plutarco y una de las variantes es que, antes de sellar el vientre de su mujer, al rey le pareció, literalmente, «ajustarlo con

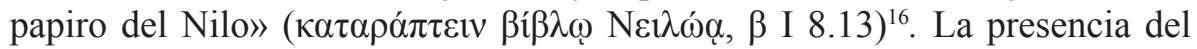
término he biblos es reveladora ya que congrega varios sentidos complementarios: la planta de papiro, la tira hecha con su tallo y el rollo de papiro procesado como material de escritura. Cada una de estas significaciones funciona en distintos niveles en la estructura de la novela. En un plano más inmediato y anecdótico, cuando el rey pide al intérprete una explicación del sueño, éste alude a la planta que crece en aquel país ${ }^{17}$ y es una imagen indicial, entre otras de este pasaje, del futuro viaje de Alejandro hacia Egipto. Ahora bien, según la Novela, Alejandro es hijo del rey egipcio Nectanebo, quien huyó de su tierra y, hospedado en la corte macedónica, se une a Olimpia disfrazado del dios-serpiente Amón, de manera que el viaje de Alejandro es,

${ }^{15}$ La recensión $\alpha$ nos ha llegado en tres versiones: el manuscrito griego A (Parisinus Graecus 1711), la traducción latina de Julio Valerio (s. IV d. C.) y la traducción armenia (s. V d. C.). La recensión $\beta$, en cambio, se nos ha transmitido en nueve manuscritos griegos (P, K, S, Q, B, M, F, V y L). El límite en la datación de $\beta$ está dado, principalmente, por la traducción armenia, cuyo autor utiliza esta fuente para completar las lagunas del texto en A. Aunque debe advertirse que la recensión $\beta$ no reescribe directamente la única versión conservada del texto griego, el manuscrito A, sino que en determinados pasajes coincide con la versión dada por Julio Valerio y la traducción armenia. Por esta razón se ha supuesto que sus innovaciones no son tales, sino que pueden proceder de una tradición más antigua o alternativa de $\alpha$. Para la caracterización de las fuentes seguimos a Jouanno 2002, p. 247 y Ruiz Montero 2007, pp. 176 ss. Para un análisis de las recensiones y sus variantes hasta la Edad Media, véase Stoneman 1996.

${ }^{16}$ Cf. traducción de García Gual 1995, p. 50: «que yo envolvía el vientre con una hoja de papiro»

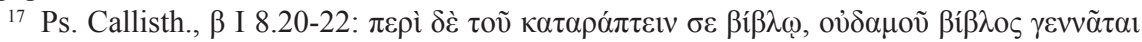

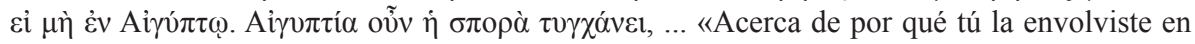
una hoja de papiro, verás. En ningún lugar se produce el papiro a no ser en Egipto. Por tanto, la simiente es egipcia, ...» 
en realidad, un regreso, un nóstos. Ahora, en un plano más profundo y simbólico, la polisemia de bíblos en tanto libro o rollo de papiro para la escritura más la referencia a Egipto anticipa la dimensión cultural de la fundación de Alejandría y de su biblioteca ${ }^{18}$.

Del mismo modo, la imagen de la serpiente, ya no sólo como la encarnación del dios Amón sino como símbolo del propio Alejandro y su ascendencia egipcia, da unidad al relato ficcional de principio a fin. Y el huevo de esa serpiente es, simultáneamente, el universo y Alejandría. Así se manifiesta tres parágrafos después, en otro hecho anticipatorio de Filipo cuando, sentado en el jardín del palacio, unos pájaros descienden hasta allí y uno de ellos deposita un huevo en su regazo. Del huevo sale una serpiente que rodea la cáscara y, al intentar volver a entrar al cascarón, muere. La interpretación del adivino es la siguiente:

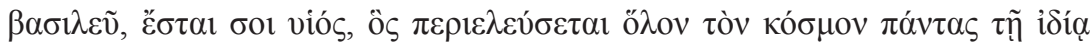

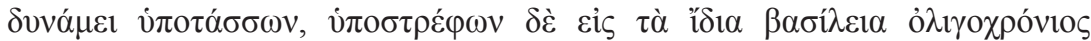

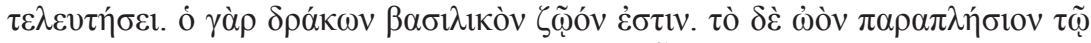

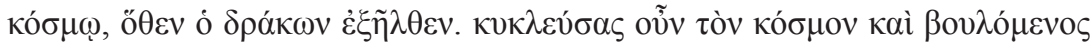

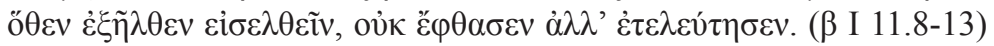

Rey, tendrás un hijo que ha de dar la vuelta al universo entero sometiendo a todos a su propio poder, pero al regresar a su reino, al cabo de pocos años, perecerá. El ofidio es un animal regio, y es una imagen del universo el huevo, de donde ha surgido la serpiente. Ya ves que, después de dar la vuelta al universo y queriendo regresar allí de donde había salido, murió antes de lograrlo ${ }^{19}$.

Más allá de las reminiscencias a la cosmogonía egipcia que subyacen en este pasaje $^{20}$, la serpiente y el huevo cobran en la Novela una significación

18 Llevando aún más lejos las posibles alusiones del término, el hecho de envolver el vientre con bíblos puede aludir, en el imaginario religioso, al futuro ritual de momificación que tendrá el cuerpo de Alejandro en tanto faraón que pasa a la inmortalidad, siguiendo el modelo de Osiris en la religión egipcia. Respecto de la vinculación metonímica entre la inmortalidad del cuerpo de Alejandro (Sôma), la biblioteca de Alejandría (conservación de cuerpos escritos) y el cosmos (cuerpo global) en Str. y Ps. Callisth., véase Nagy 2001.

${ }^{19}$ En los prodigios en torno al nacimiento de Alejandro se repite el augurio de su destino de kosmokrátor. Cf. I 7.10; I 12.16.

${ }^{20}$ Efectivamente, el imaginario general de este episodio se remonta a la cosmogonía egipcia, de donde proceden las imágenes del dios Ra-Sol, que nace del gran huevo cósmico y que representa el principio vital y la resurrección, y de la serpiente Apofis que circunda el 
propia acerca del mundo civilizado y su centro helenístico. La circularidad del retorno a Egipto, progresivamente, se va concentrando en el regreso a la ciudad que funda, ya que al final del relato, la muerte de la serpiente-Alejandro, ocurrida en Babilonia, encuentra su residencia y hogar definitivo en el monumental Sôma de la capital egipcia ${ }^{21}$. Esta alusión implícita al futuro centro cultural es aún más marcada en una variante de este pasaje en la recensión $\alpha$, donde se cuenta que al momento del presagio del pájaro y la ser-

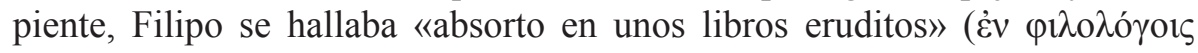

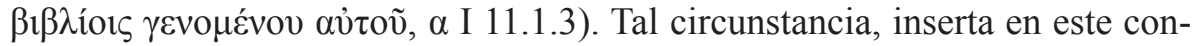
texto anticipatorio, representa más una predicción de las cualidades de Alejandro que una caracterización del propio Filipo. Su valor proléptico se confirma, además, con la reaparición de los pájaros, las serpientes y su sen-

mundo ordenado. Para un abordaje más completo de la simbología divina de la serpiente en el antiguo Egipto, véase Vázquez Hoys y Poyato Holgado 1991.

${ }^{21}$ La circularidad simbólica, no geográfica, del viaje de Alejandro resulta de ese matiz de regreso y de cierre de un ciclo que el periplo cobra en la Novela. Este matiz es señalado en varios pasajes. En primer lugar, en la inscripción en la estatua del rey Nectanebo, cuando éste huye hacia Macedonia ante la llegada de los persas (I 3.14-16): «El rey que ha huido regresará

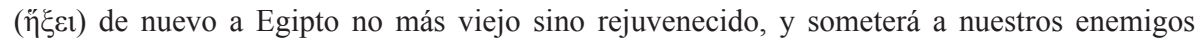
los persas». Los egipcios, al no comprender el sentido del oráculo, lo escriben ( $\gamma \rho \alpha ́ \varphi \rho v \sigma ı v$, I 3.16) en la base de la estatua de su rey. Cuando Alejandro llega a Menfis y es coronado

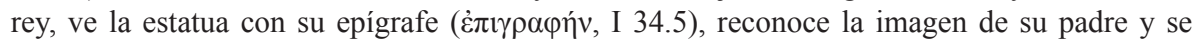
devela el oráculo en el momento de su cumplimiento. En segundo lugar, la Novela remarca el sentido de ciclo, cuando Alejandro carga sobre sus espaldas a Nectanebo muerto (I 14.39-41): «Es un estupendo milagro de la providencia que Nectanebo, siendo egipcio, recibiera honras

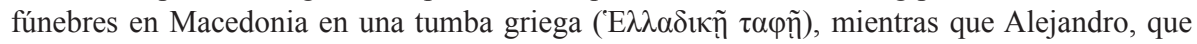

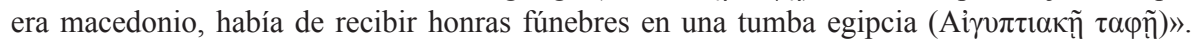
Luego, las predicciones en parte formularias de Serapis (I 33.9) y de Sesencosis (III 24.4)

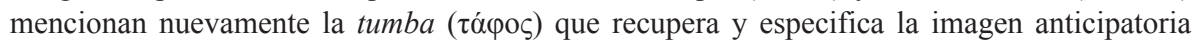
de la serpiente y el huevo en I 11.8-13, ya que esta tumba es la ciudad de Alejandría, y finalmente, el Sôma Alexándrou, donde se deposita el cuerpo momificado del héroe en III 34. Más allá del origen egipcio, el sentido de circularidad que cobra el nóstos de Alejandro se conecta estrechamente con el sentido universal de su figura regia de kosmocrátor. En el manuscrito L de la recensión $\beta$ (García Gual, 1995), se halla una anécdota fabulosa a partir de la metáfora del huevo y la serpiente cuando Alejandro, subido a unas aves gigantes, remonta los cielos y observa el mundo desde arriba. Ve entonces una enorme serpiente enroscada y, en el medio de la serpiente, un círculo: el círculo es el mundo y la serpiente, el mar que lo rodea. En este episodio, la coexistencia de pájaros, serpiente y huevo reiteran la imagen de Alejandro como dominador del mundo y como conquistador de imposibles. 
tido de imagen cósmica durante la fundación de Alejandría, como veremos enseguida.

En el periplo general, la Novela ubica la ktísis en un recorrido asombroso (I 28-34), muy diferente al de Plutarco: Alejandro llega a Egipto no por la ruta que bordea la costa oriental del Mediterráneo sino después de haber conquistado Italia y haber sido coronado «Rey de los romanos y de toda la tierra»"22. entonces atraviesa el mar hacia el sur y, avanzando por el norte de África, arriba al templo de Amón en Libia. Después sigue su ruta hacia el este, funda Alejandría y visita Menfis, donde es coronado faraón ${ }^{23}$. Otras fuentes antiguas (D.S. XVII 52; Curt. IV 8), coinciden en que la fundación de la capital se produjo después de la expedición al templo de Amón; y según algunos especialistas, ése es efectivamente el orden más verosímil de ambos episodios (Stoneman 2008 , p. 55, Pomeroy et al. 2011, p. 435). No obstante, como siempre sucede en la Novela, los datos históricos son reelaborados en clave paradoxográfica y es el elemento mágico-religioso el que favorece el sincretismo de las tradiciones egipcias y helénicas. Alejandro consulta al dios siguiendo la tradición griega de recibir la aprobación divina antes de fundar la ciudad:

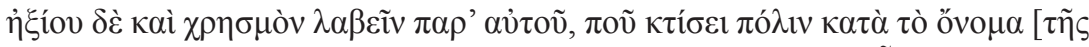

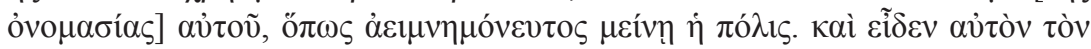

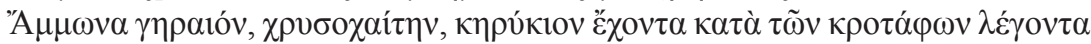

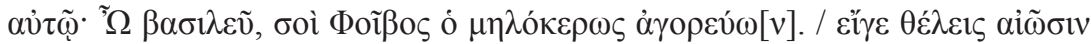

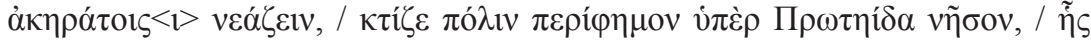

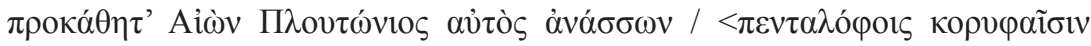

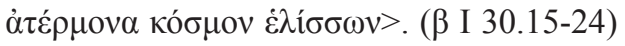

Deseaba además recibir del dios un oráculo acerca de dónde fundar una ciudad con su nombre, para que la ciudad conservara su memoria eternamente. Y tuvo

${ }^{22}$ Ps. Callisth., $\beta$ I 28-29: «Los jefes de los romanos le envían, a través del general Marco, una corona de perlas y otras de piedras preciosas con este mensaje: «Nos sumamos

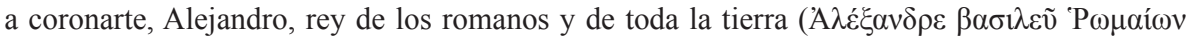

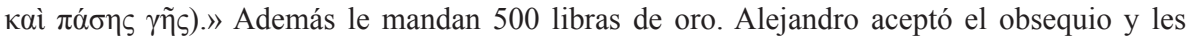

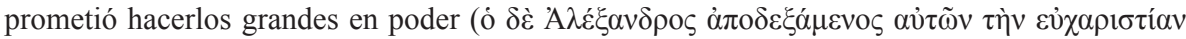

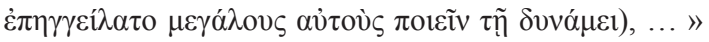

${ }_{23}$ Stoneman 2008, p. 55, considera que debió haber existido una coronación de Alejandro como faraón de Egipto y que, por lo tanto, la anécdota de la novela del Pseudo Calístenes puede ser históricamente cierta. Jouanno 2002, p. 62, en cambio, explica que se trata de un anacronismo del autor que atribuye a Alejandro momentos de la coronación establecida en tiempos de Ptolomeo y que estaban ligados a la tradición ritual faraónica egipcia. 
la visión de que Amón, anciano, de áurea cabellera, con cuernos de carnero en sus sienes, le decía: «Oh rey, a ti Febo, el de cuernos de carnero, te anuncia: si quieres rejuvenecerte en inholladas edades, funda una ciudad ilustre en la isla de Proteo, sobre la que se establezca como soberano el propio Eón Plutonio, que hará voltear en torno a sus cinco colinas el universo infinito».

La visión maravillosa de Plutarco aquí ha cambiado: ya no se da en el mismo lugar de fundación ni es Homero quien, retrospectivamente, actualiza la paideía en el presagio. Ahora, la visión ocurre en el templo y es el híbrido Amón-Febo, con cuernos de carnero en la cabeza, quien da su mensaje en prolijos versos hexámetros, como corresponde a la tradición oracular helénica. La pólis cobra, a partir de entonces, dos cualidades nuevas: el número cinco $^{24}$ y su sentido concéntrico, como un núcleo en torno al cual gravita el kósmos. En efecto, el número cinco reaparece en el momento de la fundación (I 32). La versión transmitida por $\beta$ es sensiblemente más reducida que la que transmite $\alpha$ y su carácter sumario le ha valido el desinterés por parte de la crítica: aquí ha desaparecido la gran cantidad de topónimos de las poblaciones nativas y de los canales que ocupaban el sitio de la nueva edificación, los detalles de la construcción e incluso otros sucesos que le ocurren a Alejandro allí $^{25}$. No obstante, se mantiene el episodio de los pájaros y la división de la ciudad en cinco sectores denominados con las cinco primeras letras del alfabeto griego:

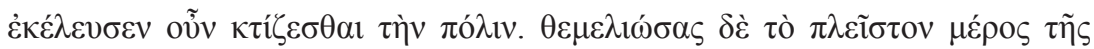

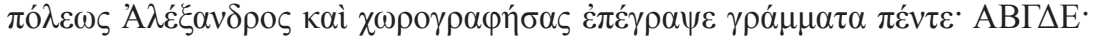

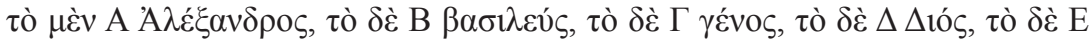

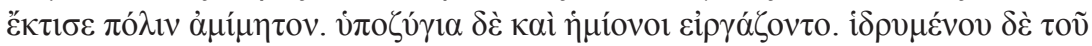

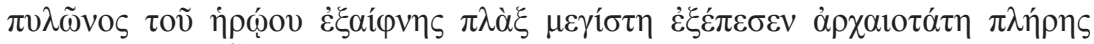

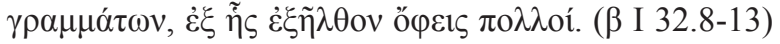

${ }^{24} \mathrm{Al}$ respecto García Gual 1995, p. 80, propone dos interpretaciones de las cinco colinas ( $\pi \varepsilon v \tau \alpha \lambda \operatorname{có}_{\varphi} \varsigma \varsigma_{\text {) }}$ del oráculo: puede aludir a los cinco elementos cósmicos de la religión persa o a las cinco partes de la ciudad. Ésta última nos parece la asociación más clara en el texto porque reaparece el número cinco en la designación de los sectores de la pólis y, en el parágrafo 33,

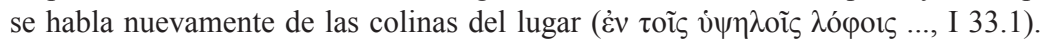

${ }^{25}$ Para un análisis de las diferencias en los relatos de fundación de ambas recensiones y de la constatación histórica de algunos topónimos mencionados en $\alpha$, remitimos a Jouanno 2002, pp. 70 y 248. 
Así que ordenó fundar la ciudad. Al poner los cimientos en la mayor parte de la ciudad y delimitar su terreno, Alejandro hizo inscribir en ellos cinco letras: $\mathrm{AB} \Gamma \Delta \mathrm{E}$. La A por «Alejandro», la B por «rey» (basileús), la $\Gamma$ por «linaje» (génos), la $\Delta$ por «de Zeus» (Diós), la E por «fundó» (éktisen) una ciudad inigualable. Bestias de carga y mulas eran utilizadas en las faenas. Al edificar el portón del templo se desplomó un enorme y antiquísimo entablamiento recubierto de letras. Bajo él salieron muchas serpientes que se deslizaron reptando por las entradas de los edificios en construcción.

Ambos momentos de la ktísis (transmitida por $\beta$ ), basados en información histórica, conforman una unidad narrativa trabajada a nivel ficcional y saturada de implicancias míticas que integran el episodio en el periplo novelesco de Alejandro, reforzando la unidad del relato. Así como en el pasaje de la diagramación en Plutarco cobraba importancia el sello de identidad poética (homérica) y cultural de la forma de la clámide, en Pseudo Calístenes la delimitación de la ciudad está dada por límites geográficos y nominales: la longitud (límites occidental y oriental) abarca desde el río 'Serpiente' hasta el río 'Buena Fortuna'26. Estos topónimos aluden a canales cuya existencia real ha sido atestiguada en la ciudad antigua. Pero lo significativo es que lo que $\beta$ pierde en información localista lo gana a favor del sentido novelesco de esa significación nominal, enfatizando la coherencia interna de la narración ${ }^{27}$. Ha sido Paschalis 2007 quien, en su estudio comparativo de las versiones griegas y latinas de la Novela, ha señalado que los topónimos en la recensión $\beta$ tienen menos significación geográfica que ficcional, ya que cobran una dimensión semántica dada por la lógica inventiva del relato. En continuidad con este planteo, creemos que los topónimos que delimitan la ciudad explican la presencia física y la trascendencia simbólica de los animales presentes en esta versión de la ktísis: Drákon, la serpiente, relacionada siempre con Alejandro conquistador, y Agathodaimon, la deidad protectora del futuro cultural de la nueva pólis.

${ }^{26}$ Ps. Callisth., $\beta$ I 31.28-30: «Siguiendo los mandatos del rey Alejandro, delimitan la

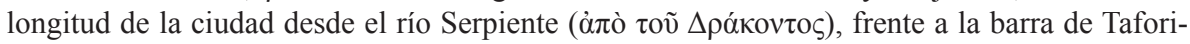

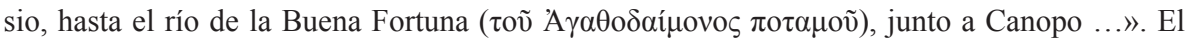
parágrafo 31 se considera una interpolación de época romana en la secuencia de los parágrafos 30 y 32 , pertenecientes a una versión anterior.

27 Con respecto a los topónimos de este pasaje y su explicación etimológica ficcional, véase Jouanno 2002, p. 73. 
Este episodio se complementa con el siguiente, cuando Alejandro ordena señalar el perímetro y se relata el prodigio de los pájaros (I 32.1). De todas las variantes que este evento tiene en las fuentes indirectas, Plutarco y Pseudo Calístenes ofrecen la misma versión: son los pájaros que comen el dibujo de la harina los que presagian la abundancia y prosperidad de la ciudad ${ }^{28}$. La presencia de las aves reaparece en otras fuentes imperiales (V. Max., Curt., etc.), incluso se ha defendido el valor histórico de ese supuesto prodigio, con las aves del lago Mareotis que frecuentemente llegan a la ciudad (Le Roy 1981). Sin embargo, como ocurre con los demás elementos, esa presencia cobra una connotación diferente en el co-texto de la Novela: en la interpretación del presagio, reaparece la idea centrífuga de Alejandría, ya que los hombres nacidos en la ciudad se esparcirán como los pájaros que «viajan en torno al mundo civilizado ${ }^{29}$. Le Roy 1981 ha reconocido los planos simbólicos implicados en esta versión de la ktísis: el aire, representado con los pájaros; el plano humano, con la harina; y el plano subterráneo, con las serpientes tutelares. Dice el autor (1981, p. 406): «Pour Alexandrie, capitale universelle, fondée par le roi-dieu maître de l'Univers, il ne fallait pas moins que l'Univers entier pour servir de garant. Ainsi, quand le Roman d'Alexandre juxtapose le conte d'Agathodaimôn et celui des oiseaux, il ne s'agit nullement d'une rencontre fortuite, mais bien d'une composition tout à fait coherente».

Ahora, se ha enfatizado el aspecto literal que cobra la ktisis y la denominación de los sectores de la ciudad con las cinco primeras letras del alfabeto griego: АВГ $\triangle \mathrm{E}$. Este dato histórico ${ }^{30}$ es reelaborado ficcionalmente por el novelista, quien transforma la secuencia alfabética en un acrónimo que narra el acto de fundación: «La A por «Alejandro», la B por «rey», la $\Gamma$ por «linaje»,

${ }^{28}$ Una diferencia entre Plu. y Ps. Callisth., $(\beta)$ es que el primero justifica el uso de la harina con la falta de cal, dando un argumento verosímil del hecho, mientras que el segundo no menciona ninguna causa. En la recensión $\alpha$, la harina es una ofrenda propiciatoria de fundación de carácter ctónico, asociada a las serpientes y al Agathodaímon. Al respecto, véase Le Roy 1981, p. 73.

29 Ps. Callisth., $\beta$ I 31.6-8: «La ciudad que has ordenado construir alimentará al mundo civilizado y por doquier habrá hombres nacidos en ella. Pues las aves recorren todo el mundo

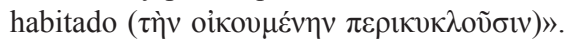

${ }^{30}$ Desde el siglo $\mathrm{V}$ a. C., las letras del alfabeto se utilizaban para la denominación de tribus en Atenas. Cf. Arist., Ath. 63.2-4. Sobre la organización de Alejandría en cinco sectores, véase Jouanno 2002, p. 75 y Stoneman 2008, p. 56. 
la $\Delta$ por «de Zeus», la $\mathrm{E}$ por «fundó» una ciudad inigualable». En el paso de las letras como unidades asignificantes a las letras como narración, el texto

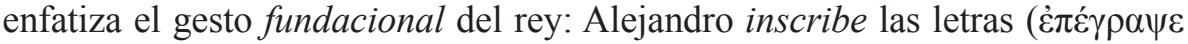
$\gamma \rho \alpha ́ \mu \mu \alpha \tau \alpha)$ en los cimientos. En consecuencia, la versión paradoxográfica de la fundación de Alejandría crea una imagen literaria que resume toda una época: la ciudad se edifica sobre la letra griega escrita en sus bases y, de ese modo, el alfabeto ahora también simboliza el enciclopedismo que, como ha explicado Sirinelli 2001, distingue el proyecto de Alejandría y de sus edificios en la dinastía ptolemaica. La escritura griega deviene la clave de la universalidad: ese es el ideal alejandrino que alimenta la Gran Biblioteca. De hecho, este relato ficcional postula, en clave narrativa, la nueva tradición cultural griega que funda Alejandro en el momento que funda la ciudad.

La reiteración de los grámmata en el episodio siguiente de las serpientes, tal como nos ha llegado, parece una incorporación particular de la recensión $\beta$. En la versión de $\alpha$, una vez iniciada la construcción, Alejandro mata una serpiente que aterrorizaba a los obreros y retardaba la edificación de la ciudad (I 32.6). Luego, cuando se construye el templo, presumiblemente dedicado al Agathós Daímon (Jouanno 2002, p. 75), salen desde un arquitrabe serpientes benéficas que entran en las casas (Ps. Callisth., $\alpha$ I 30.10). En la recensión $\beta$, la muerte de la serpiente desaparece y la versión del templo presenta una pequeña variante: en la edificación se produce el derrumbe de un entablamento de piedra muy antiguo inscripto con letras $(\gamma \rho \alpha ́ \mu \mu \alpha \tau \alpha)$, debajo del cual surgen serpientes que entran en las obras en construcción. El texto recuerda, entonces, que esos animales son respetados como garantes de la protección

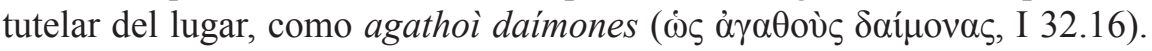

La modificación es mínima, pero a nuestro entender, significativa. Es claro que la presencia de las serpientes en este pasaje tiene un valor positivo y que favorece la imagen de Alejandro como héroe sauróctono ${ }^{31}$. La pregunta es, en todo caso, ¿qué hacen las letras en este asunto y de qué grámmata se trata? La secuencia narrativa nos muestra, en el episodio anterior, la inscripción en las bases de la ciudad de cinco grámmata, letras griegas. Por la cercanía de ambos eventos, el lector puede pensar que los grámmata inscriptos en la piedra son griegos; sin embargo, el calificativo de «entablamento muy antiguo»

${ }^{31}$ Jouanno 2002, p. 76, vincula esta anécdota con la imagen sincrética de Alejandro como hijo del dios serpiente Amón. Stoneman 2008, p. 56, observa que la serpiente representa al dios egipcio del destino, Shai, y que una serpiente aparece en imágenes de Alejandro Fundador. 
hace deducir, por lógica, que se trata de grafemas egipcios. Lo interesante es que el texto favorece el equívoco y, en este caso, la ambigüedad es productiva: por un lado, se edifica un nuevo templo y, en este preciso momento, se derrumba una parte cubierta de letras y de allí surgen las serpientes tutelares. La anécdota condensa el encuentro entre pasado, presente y futuro, el fin de un dominio que se continúa en el comienzo de otro, y esa imagen está centrada, además, en la continuidad de las letras (la cultura escrita, los grámmata) y las serpientes, que aseguran la fortuna de la metrópolis. De modo que los nombres de los ríos, que dan la demarcación geográfica de la ciudad, ahora cobran significación en la anécdota, con la mediación de los signos escritos.

Este motivo se reitera en otra variante de $\beta$, que cierra la ktisis con un elogio de Alejandría (I 33). El rey, siguiendo el oráculo de Amón (que el texto cita nuevamente aquí), busca en las colinas el templo de Sérapis y rinde sacrificios al dios que vigila la ciudad y el universo infinito: la repetición léxica que se da tanto en el oráculo de Amón como en el voto de Alejandro

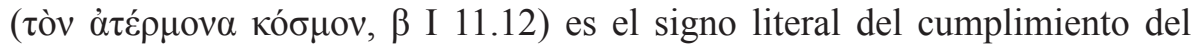
oráculo $^{32}$. Además, el augurio propicio del águila que traslada las ofrendas del sacrificio desde el altar nuevo hasta el altar antiguo de Zeus y Hera (sincretismo textual de los dioses Sérapis e Isis), conduce a Alejandro hasta los

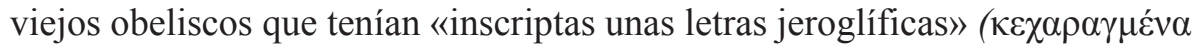

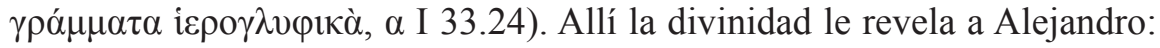

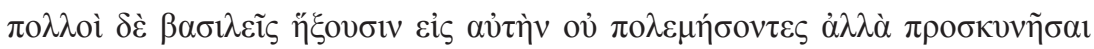

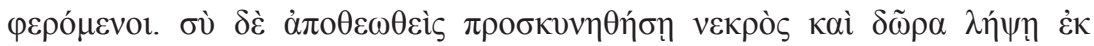

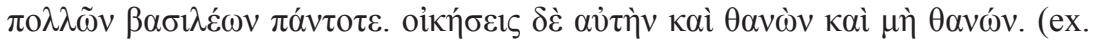

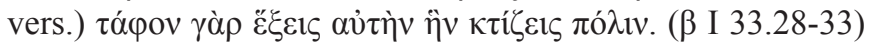

Muchos reyes acudirán a ella, no para guerrear, sino invitados a rendirle sumisión. Tú, convertido en dios, serás adorado después de muerto y recibirás presentes de numerosos reyes siempre, y habitarás la ciudad muerto y no muerto. Porque tendrás como tumba la ciudad que fundaste.

Este oráculo, que en la versión de $\alpha$ es dado al rey mediante la aparición del dios, en $\beta$ aparece como mensaje escrito: son las letras las que guardan celosamente la predicción sobre el futuro glorioso de Alejandría.

${ }^{32}$ Ps. Callisth., $\beta$ I 11-13: «Que eres el dios providencial de esta tierra y velas también en el universo ilimitado, esto es evidente». 
Si se consideran los episodios de la recensión $\beta$, se advierte que esa secuencia (I 30-33) forma una unidad simbólica, donde los datos históricos se saturan de connotaciones ficcionales en función de un relato mítico de fundación: el oráculo de Amón; la diagramación dada por los canales Drákon y Agathodaimon; las aves que devoran la harina; la circularidad de la oikouméne; los grámmata que se inscriben en la base de la pólis; los viejos grámmata en continuidad metonímica con las serpientes tutelares (agathoì daímones); la reiteración del oráculo de Amón y su contrapartida, el oráculo de ZeusSérapis, grabado en letra (egipcia).

Más acá y más allá de la ktísis, la novela recupera la preeminencia de la capital helenística que guarda el cuerpo inmortal del héroe y la memoria letrada $^{33}$. Ya avanzado el tercer y último libro, Alejandro consulta el espíritu del emperador Sesoncosis para preguntarle sobre su futuro. La imagen le da la bienvenida llamándolo «afortunado: Pues tienes un nombre inmortal, por haber fundado en Egipto la muy admirada Alejandría» ( $\beta$ III 24.8-9). Cuando el macedonio pregunta cuántos años vivirá, la imagen no responde pero le

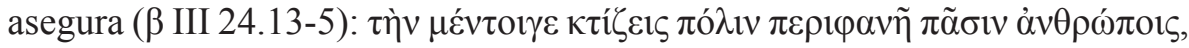

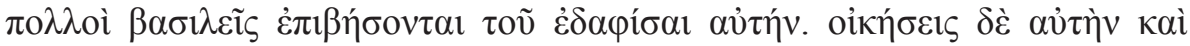

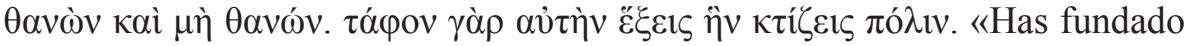
una ciudad muy ilustre entre todos los hombres. Muchos reyes la atacarán con intención de arrasarla, pero tú la habitarás, después de muerto y sin morir. Tendrás como tumba la ciudad que fundaste». Este presagio de estructura formularia reitera el dado por Sérapis en I 33.28. En ambos se hace alusión a los futuros basileîs que acudirán a la ciudad, pero con intenciones diferentes, según uno u otro oráculo. El primero menciona a los reyes que irán a la ciudad, no a guerrear sino a rendir culto divino ( $\pi \rho \circ \sigma \kappa v v \tilde{\eta} \sigma \alpha l)$ al cuerpo de Alejandro; el segundo advierte que muchos reyes intentarán arrasarla

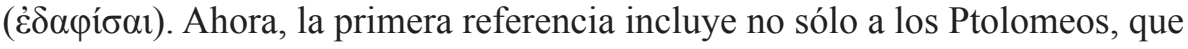
impulsarán el culto divino del héroe y construirán el Sôma Alexándrou, sino que se extiende a los emperadores romanos quienes, movilizados por la imitatio Alexandri, llegarán a la capital egipcia para rendirle tributo al cuerpo del macedonio. De igual manera, la segunda mención a los reyes que preten-

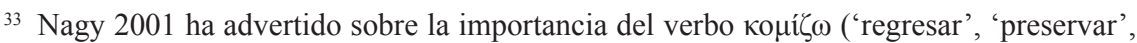
'conservar'), usado en Str. XVII 1.8 y en Ps. Callisth. III 34.2, 9, para nombrar la preservación (momificación) del cuerpo del Alejandro en continuidad con la preservación de textos literarios en la biblioteca de Alejandría. 
derán arrasarla, alude tanto a los enfrentamientos entre los diádocos ${ }^{34}$ como a las luchas que convulsionarán la capital en período romano, desde César hasta Caracalla y los conflictos de los ss. III, IV y V d. C. Finalmente, el vaticinio sobre las continuas revueltas que sufrirá la ciudad que guarde el cuerpo de Alejandro advierte, otra vez en clave mágica, acerca de las fisuras políticas, religiosas y étnicas no resueltas del ideal cosmopolita y multicultural del sueño helenístico.

La Novela se cierra con la lista de las Alejandrías fundadas por Alejandro $^{35}$ que, en su enumeración asindética extienden y multiplican, con su nombre, el alcance universal de la empresa del macedonio. El afán de universalidad de la ciudad, de metrópolis de todo el mundo habitado ( $\mu \eta \tau \rho o ́ \pi o \lambda \iota v$

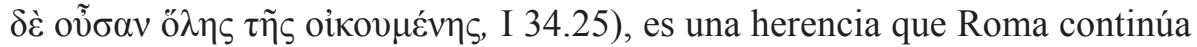
y hace suya ${ }^{36}$. Sin embargo, la palabra oikov $\mu \varepsilon ́ v \eta$ en la Novela delimita ese territorio de conquista ficcional que incluye Roma y la pre-dice: la kosmópolis alejandrina se carga de un sentido anticipatorio, donde Roma puede reconocerse y a la vez perpetuarse como urbs mundi. Así, la ktísis se convierte en el motivo que articula y cohesiona todas las peripecias increíbles de Alejandro. El viaje dibuja un nóstos en espiral, como los anillos de una serpiente narrativa (Egipto-Macedonia-Egipto/ Alejandría-Babilonia-Alejandría), que asegura la inmortalidad del nombre de Alejandría como centro del universo, como kosmópolis, y esa inmortalidad está fundada en la letra escrita y en el sincretismo cultural.

En conclusión, ambas versiones imperiales de la ktísis de Alejandría imprimen en el origen de la ciudad las marcas de la cultura letrada que ella misma gestará para los tiempos venideros. Sin embargo, entre Plutarco y Pseudo Calístenes no sólo son recognoscibles fuentes directas y gérmenes narrativos comunes que, no obstante, cobran diferentes alcances en uno u otro, sino la proyección de ese mundo libresco. Mundo que tiene en Plutarco a uno de sus exponentes más reconocidos, con la fuerte impronta helénica de ese proyecto, y en el Pseudo Calístenes $(\beta)$, una muestra tardía de aquella

\footnotetext{
${ }^{34} \mathrm{Al}$ respecto, remitimos a los estudios de Lévêque 2006 y Evans 2008, entre otros.

${ }^{35}$ Según Jouanno 2002, p. 19, se trata en realidad de fundaciones seléucidas, pero que atribuidas aquí al macedonio, conformarían una estrategia de propaganda de la autoridad heredada de la dinastía Lágida.

${ }^{36}$ De Polignac 2003, p. 153, advirtió la relación entre este encomio de Alejandría y el Elogio a Roma de Elio Arístides. Los tópicos de la ciudad eterna, madre de ciudades, centro del mundo habitado, son comunes en ambas piezas.
} 
cultura, que subyace en la Novela aunque sin exhibir ya una comprensión cabal de los conocimientos (egipcios, persas, griegos, romanos, etc.) que la formaron (De Polignac 2003). Sin embargo, el olvido del sentido más erudito, en la recensión $\beta$, no es una pérdida sino un cambio de significación en favor de la coherencia novelesca, que logra un héroe más universal a medida que deviene más fabuloso: un héroe autorreferencial, cuyas características le son dadas por las aventuras ficcionales que el escriba (tras el nombre del Pseudo Calístenes) cuenta y agrega y corrige y olvida y reinventa. Acerca de la impronta libresca que ese héroe y la ciudad que fundó tienen, valga el testimonio de las sucesivas copias, reescrituras y traducciones de la Novela de Alejandro en el imperio romano, bizantino y en el Medioevo.

\section{BIBLIOGRAFÍA}

Ediciones y traducciones:

Bergson, L. 1965: Pseudo-Callisthenes. Der griechische Alexanderroman. Rezension $\beta$, Estocolmo.

Cortés Copete, J. M. 1997: Elio Arístides. Discursos IV, Madrid.

García Gual, C. 1995 ('1977): Pseudo Calístenes. Vida y Hazañas de Alejandro de Macedonia, Madrid.

Guzmán Guerra, A. 1986: Plutarco / Diodoro Sículo. Alejandro Magno, Madrid.

Kroll, W. 1926: Pseudo-Callisthenes. Historia Alexandri Magni. Recensio a sive Recensio vetusta, Berlín.

Ziegler, K. 1968: Plutarchi. Vitae Parallelae, Alexander, vol. 2.2, Leipzig.

Bibliografía citada

Chialva, I. 2012: «Acerca de la historia y la ficción en tres versiones imperiales de la fundación de Alejandría», Circe 16, pp. 43-56.

De Polignac, F. 2003: «Décomposition et recomposition d'une culture savante. L'exemple des Vies d'Alexandre», en Jacob, C. (ed.), Des Alexandries. Les Métamorphoses du Lecteur. Vol. II, París, pp. 145-157.

Dougherty, C. 1994: «Archaic Greek Foundation Poetry: Questions of Genre and Occasion», JHS 114, pp. 35-46.

Evans, J. A. 2008: Daily life in the Hellenistic age from Alexander to Cleopatra, Westport-Londres.

Jouanno, C. 2002: Naissance et métamorphoses du Roman d'Alexandre, París. 
Larmour, D. 2000: «Metaphor and metonymy in the rhetoric of Plutarch's Parallel Lives», en Van der Stockt, L. (ed.), Rhetorical Theory and Praxis in Plutarch, Namur-Lovaina, pp. 265-279.

Le Roy, C. 1981: «Les oiseaux d'Alexandrie», BCH 105, pp. 393-406.

Lévêque, P. 2006 ( $\left.{ }^{1} 1992\right)$ : El mundo helenístico, Buenos Aires.

López Salvá, M. 1997: «Plutarco y Alejandro Magno», en Schrader, C. et al. (eds.), Plutarco y la Historia. Actas del V Congreso Español sobre Plutarco, Zaragoza, pp. 261-270.

Mestre, F. 2008: «Uso y abuso de los libros en un mundo libresco: algunos ejemplos griegos de la época imperial», Faventia 30, pp. 297-313.

Nagy, G. 2001: «Homère comme modèle classique pour la bibliothèque antique: les métaphores du corpus et du cosmos», en Guiard, L. y Jacob, C. (eds.), Des Alexandries. Du livre au texte. Vol. I, París, pp. 43-49.

Paschalis, M. 2007: «The Greek and Latin Alexander Romance: Comparative Readings», Ancient Narrative. The Greek and the Roman Novel 8, pp. 70-102.

Plácido, D. 1995: «L'image d'Alexandre dans la conception plutarchéenne de l'Empire Romain», DHA 21, pp. 131-138.

Pomeroy, S., Burnstein, S., Donlan, W. y Tolbert, J. 2011: La Antigua Grecia. Historia política, social y cultural, Barcelona.

Rodríguez Adrados, F. 2000: «Las imágenes de Alejandro», en Alvar, J. y Blázquez, J. M. (eds.), Alejandro Magno. Hombre y mito, Madrid, pp. 15-31.

Ruiz Montero, C. 2007: La novela griega, Madrid.

Santana Henríquez, G. 2005: «La educación de Alejandro en las Vidas Paralelas: la paideia griega en Plutarco», en Jufresa, M., Mestre, F., Gómez, P. y Gilabert, P. (eds.), Plutarc a la seva època: paideia i societat, Barcelona, pp. 637-646.

Sirinelli, J. 2001: «Alexandrie royaume du livre», en Guiard, L. y Jacob, C. (eds.), Des Alexandries. Du livre au texte. Vol. I, París, pp.43-49.

Sistakou, E. 2008: «Beyond the Argonautica: In search of Apollonius' ktisis poems», en Papanghelis, T. y Rengakos, A. (eds.), Brill's Companion to Apollonius Rhodius, Leiden-Boston, pp. 311-340.

Stoneman, R. 1994: «Alexander Romance: from Histoy to Fiction» en Morgan, J. R. y Stoneman, R. (ed.), Greek fiction. The Greek Novel in Context, Londres, pp. 117-119.

Stoneman, R. 1996: «The metamorphoses of the Alexander Romance», en Schmeling, G. (eds.), The Novel in the Ancient World, Mnemosyne 159, Leiden, pp. 601-612.

Stoneman, R. 2008: Alexander The Great. A Life in Legend, North Yorkshire.

Tarbell, F. B. 1906: «The form of the chlamys», CPh 1, pp. 283-289.

Whitmarsh, T. 2002: «Alexander's Hellenism and Plutarch's textualism», CQ 52, pp. 174-192. 
Whitmarsh, T. 2004: Ancient Greek Literature, Cambridge.

Vázquez Hoys, A. M. y Poyato Holgado, C. 1991: “"Aquella que ama el silencio”:

Sobre la serpiente en los antiguos cultos egipcios», ETF(hist) 4, pp. 37-72.

Fecha de recepción de la primera versión del artículo: 15/04/2016

Fecha de aceptación: 21/06/2016

Fecha de recepción de la versión definitiva: 14/07/2016 